\title{
THE INFLUENCE OF BABY WALKER USAGE IN THE SENSORY MOTOR DEVELOPMENT OF CHILDREN AT SCHOOLS IN EARLY CHILDHOOD EDUCATION
}

\author{
Pâmela Pissolato Schopf ${ }^{1}$, Christian Caldeira Santos ${ }^{2}$
}

\section{ABSTRACT}

DOI: http://dx.doi.org/10.7322/jhgd.102998

\begin{abstract}
Introduction: infant's healthy development acquisition is related to sensorial and motor experiences acquired in their first living year. As a walking stimulating aid, parents believethat baby walker may anticipate walking. Objective: check the frequency of the use of child walker for infants and the influence of this procedure on the sensory motor development, and correlate the daily time spent with the acquisition of independent walking at 13 months. Methods: Initially, parents answered a questionnaire regarding the use or no use of the baby walker. Infants who used it developed walking skills earlier than those who did not use it $(p=0.044)$. Results: Daily time of use influenced in the walk acquisition time $(p=0.005)$; and there was no association between the groups who used or did not use the baby walker compared to their current motor development assessed by Alberta Infant Motor Scale $(p=0.566)$. Conclusion: We concluded that the vesting period of the march is on the daily use of the walker, which is an important factor for this acquisition.
\end{abstract}

Key words: infants, infant development, baby walker.

\section{INTRODUCTION}

Acquisitions and the increase of milestones occur with different motors and unstable rhythms within a group of individuals and are presented in a linear fashion, occurring in periods in which a child acquires many skills and other behavioural plateaus marked by highlighting great variability in the first year of life, requiring improvement of the conquered skills in order to sustain primary movement ${ }^{1-3}$.

The sensorimotor experiences of this period facilitated the acquisition and refinement of these standards, and will be enriched by neurological maturation, task specific, variability and complexity of the environment in which the child lives ${ }^{3}$, so your body is getting stronger, and balance training coordination to perform the transposition of all sequential postures.

The process of transition from a four support posture for a bipedal posture and then the acquisition of the march passes through a predetermined evolutionary process allowing benefits and a broader view of the environment, in addition to the release of the upper limbs for manipulation and exploitation of objects thereby allowing the discovery of a new environment and new opportunities ${ }^{4}$.

The fact want the child walking alone and quickly makes many parents resort to strategies which skip the logical sequence of motor milestones; one of the strategies used is the use of baby walker4-5. This is defined as a wheeled base supporting a rigid frame which supports a seat with leg openings and usually a plastic tray ${ }^{6}$.

One of the core strengths of the use of baby walker is the fact serve as a facilitator of practice, during a period in which the child does not possess the ability to get around and explore the environment in the standing posture ${ }^{4}$.

In contrast to this argument clinical assumptions admit that the gait pattern can be changed, leading to the center of gravity displacement providing the wrong foot contact with the ground; this way the biomechanical alignment of the lower limbs and the body is changed, causing a delay in the acquisition of milestones; serious injuries as well as head injuries, these being the main cause of death and morbidity during infancy. ${ }^{4-7}$

The objective is to check the frequency of the use of baby walker for infants and the influence of this procedure on the sensory motor development, and correlate the daily time spent with the acquisition of independent walking at 13 months.

\section{METHODS}

This study is characterized as a quantitative field research, transverse and descriptive. Where were included in the study

\footnotetext{
1 Fisioterapeuta, Mestranda em Gerontologia Biomédica - Instituto de Geriatria e Gerontologia da Pontifícia Universidade Católica do Rio Grande do Sul (PUCRS), Porto Alegre, Rio Grande do Sul, Brasil.

2 Professor Assistente na Universidade Federal do Pampa - UNIPAMPA, especialista em fisioterapia neurológica, Uruguaiana/RS. O respectivo trabalho foi realizado pela Universidade Federal do Pampa (UNIPAMPA), Uruguaiana, Rio Grande do Sul, Brasil.

Corresponding author: Pâmela Pissolato Schopf. E-mail: pp.schopf@hotmail.com
}

Suggested citation: Schopf PP, Santos CC. The influence of use of sensory motor walker on the development of children at schools in early childhood education. Journal of Human Growth and Development. 25(2): 156-161. DOI: http://dx.doi.org/ $10.7322 /$ jhgd.102998

Manuscript submitted: mar 22 2014. Accepted for publication: Dec 102014. 
20 children aged between 12 and 18 months, which were frequenters of two elementary schools in the city of Uruguaiana. The mode of choice of schools was by randomization through simple drawing of lots among the schools that obtained the same feature. The reason for the choice was the fact that these children possess sufficient to represent the city of children universe for this outcome that made up 21 children. Thus, the directors of preschools Home Children were sent: Our Lady of Lourdes and the Municipal School of Education Child Cottage Emilia, the cover letter and authorization so that they were aware of the work to be done by allowing or vetoing to achieve the same. After the consent of the direction, the data collection was carried out by one researcher.

To be included in the study, parents were invited to participate in the study, noting that no physical risk applies to the experiment, however were told that the observation reviewer could present some embarrassment to the child. Were excluded from the study children whose parents reported history of physical disabilities, brain injury, premature birth, syndromes and children major 18 months old.

Those who agreed to participate were asked to fill out a questionnaire with structured and semi-structured questions in the presence of the researcher and sign the consent form and clarified.

The questionnaires collected were separated into two groups: Group A, children who used baby walker, and Group B, children who did not use. From the responses it was found the frequency of use of baby walker for children 12 to 18 months, the two elementary schools in the city.

The influence of baby walker in the sensory motor development stimulus in these children was verified through a motor evaluation, which we used the Alberta Infant Motor Scale (AIMS) which encompassed age 0-18 months. Assessments of children were held at the school in the mornings and afternoons, after left by those responsible on site. After evaluating, two groups were analyzed. Both groups suffered from comparison of the scores obtained in the percentile curves graph, using the Student's T test.

The AIMS is an observational tool designed to assess the evolution of the motor development of infants at term and preterm, from 38 weeks gestational age up to 18 months corrected age, quantifying in 58 items the motor patterns and postures child8-9.

These items are grouped into four subscales, which describe the development of spontaneous movement and motor skills in the prone position ( 21 items), supine ( 9 items), sitting (12 items) and standing (16 items), and the examiner notes the presence of weight support, posture and antigravity movements in each of these positions.

Upon review, we identified the current motor skills in motor repertoire of the child, marking the skill less and more evolved (motor development window); each observed item received one (01) point and each item not observed received a score of 0 (zero).

The items prior to motor development window received 01 point each, as it is believed that the child has already incorporated these motor skills previously.

The credits of each sub-scales were summed and from this a total score across the AIMS (0-58 points) was assigned and converted into per- centile ranking chart (percentile $X$ Chronological Age Corrected).

At the end ranked according to the performance engine child: normal/expected ( $>25 \%$ percentile of the curve), suspected motor performance ( $\leq 25$ and $>5 \%$ of the curve) and abnormal motor performance ( $\leq 5 \%$ of the curve $)^{8}$.

To know the correlation between independent walking at 13 months and the time of day stay in baby walker, was made through in the questionnaire answered by the parents and was assessed by the Pearson correlation coefficient, classifying the correlation as perfect $(r=1)$, strong $(r>0.75)$, moderate $(r>0.5)$, weak $(r<0.5)$ and RT $(r=0)$.

Analyses were performed using SPSS version 17.0 for Windows. Descriptive statistics and tests of normality (Shapiro-Wilk test) were determined for all variables. From the results we applied the average comparison test as the Test T-Student with $5 \%$ significance level for all tests.

The sample size calculation was conducted using the equation $E / S$ where $E=$ a clinically significant difference in the outcome variable and corresponds to $\mathrm{S}=$ sample standard deviation of the same variable. Whereas $25 \%$ of variation in scores of Alberta Infant Motor Scale Rating Scale and considering a $\alpha=0.05$ and $\beta=0.2$, it took 21 children to power sample.

The project was approved by the Ethics Committee on Human Research of the Federal University of Pampa (Unipampa) of Protocol No. 221.068.

\section{RESULTS}

A total of 25 questionnaires were delivered by parents of children enrolled in the two schools, and four $(16 \%)$ of these had to be excluded from the study due to the age of the children exceed 18 months and one (4\%) due medical certificate of temporary removal from school. So for statistical analysis counted a total of twenty children ( $n=20)$, ten with boys and ten girls, divided into group A (children who used baby walker) and group B (children did not use the baby walker). Obtained a similar frequency in both groups, as $50 \%$ of parents opted for the use of baby walker with their children and $50 \%$ preferred not to use it.

Faced with the motor evaluation performed by AIMS found that of 20 children, nine had normal development/expected for age (above 25 percentile scores), four group $A$ and five in group $B$, a child of $B$ group had suspected development (score between 5-25), while ten children 
presented motor delay ( $\leq 5$ scores) with six group $A$ and four in group $B$ which can be seen in Figure 1.
In general, there was a greater number of children who had not suitable percentiles for age, 11 children in the sample had motor poor

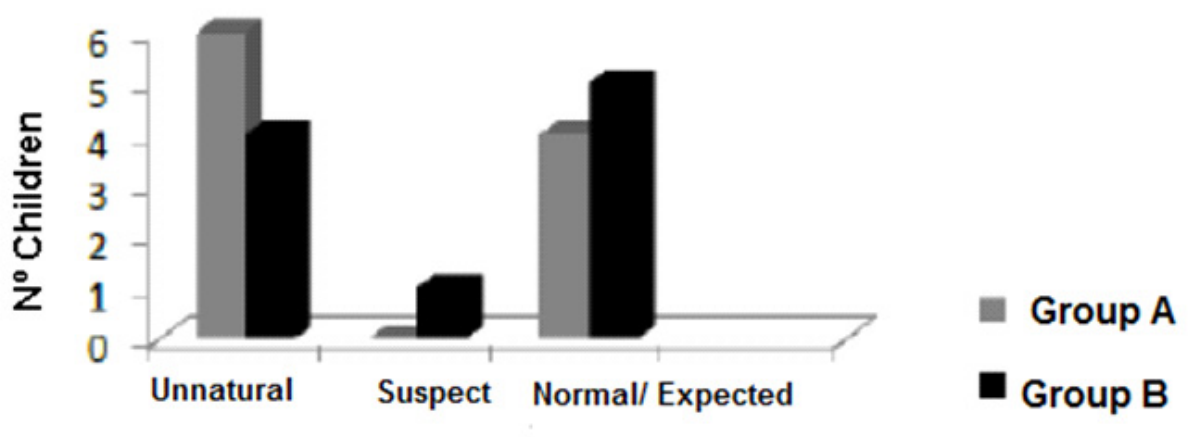

Classication

$\rho=0,566^{*}$

Figure 1: Walker influence of motor development

Motor rating according to AIMS intergroup.

performance (percentile $<25 \%$ ), but no statistically significant association between the groups ( $p=0.566$ ) using or not the baby walker, as the motor performance. The fact that the sample find yourself in an age group on average
486.05 days \pm 60.09 days might have contributed to the final score of the AIMS, since that this is a development period of motor skills achieved.

When asked parents about your child if he acquired independent walking at 13 months of

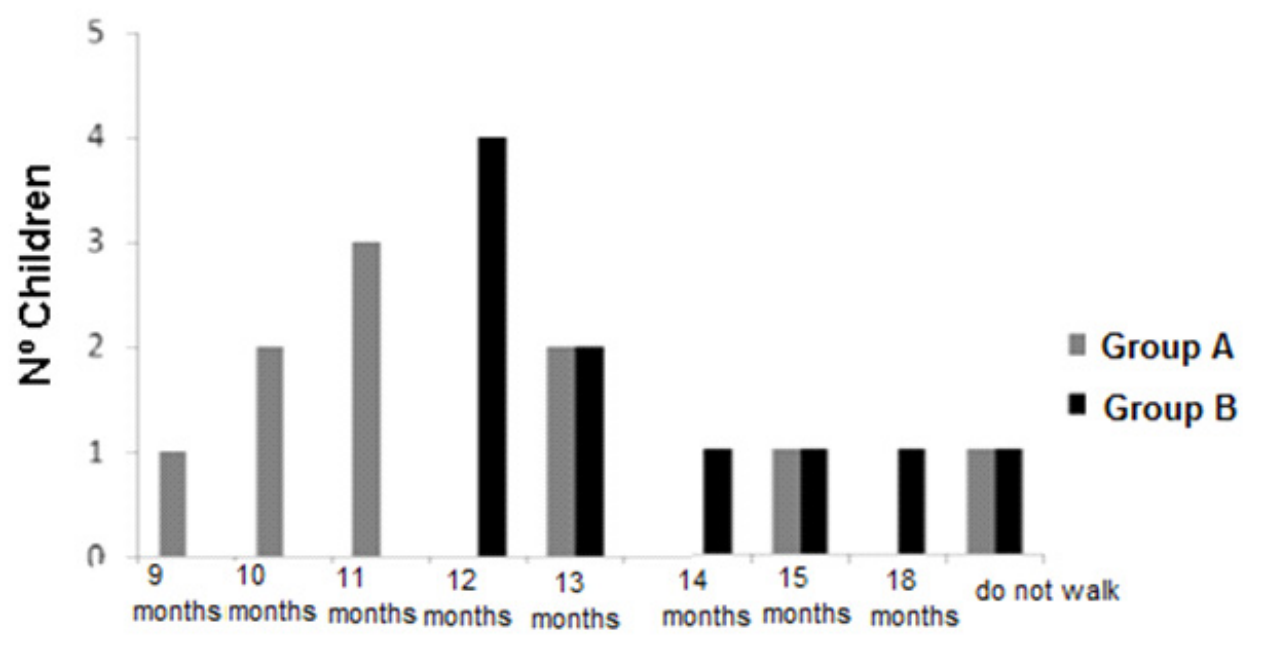

Early march

Figure 2: Walker influence of motor development

Age acquisition of independent walking between groups $A$ and $B$.

life, the result of the universe studied showed 14 positive responses, against six negative. Figure 2 shows the frequency of age (months) in which children develop this ability. The results revealed that the age of gait acquisition between groups were more prevalence between 11 and 13 months, since children belonging to group $A$ developed to march on average at 11.44 months \pm 1.87 months and the group $B$ on average at 13.44 months \pm 2.00 months, with significant 
difference between groups $(p=0.044)$. It is also observed two cases in which the gear has not yet been acquired, with children belonging to the group $A$, and 13 months using the baby walker from 8 months, daily for at least 1 hour and other also 13 months and belonging to the group $B$. How common report of these two mothers was the difficulty of children in acquiring bipedal posture, while the mother of the Group A added that his son jumped the phase of the crawl.

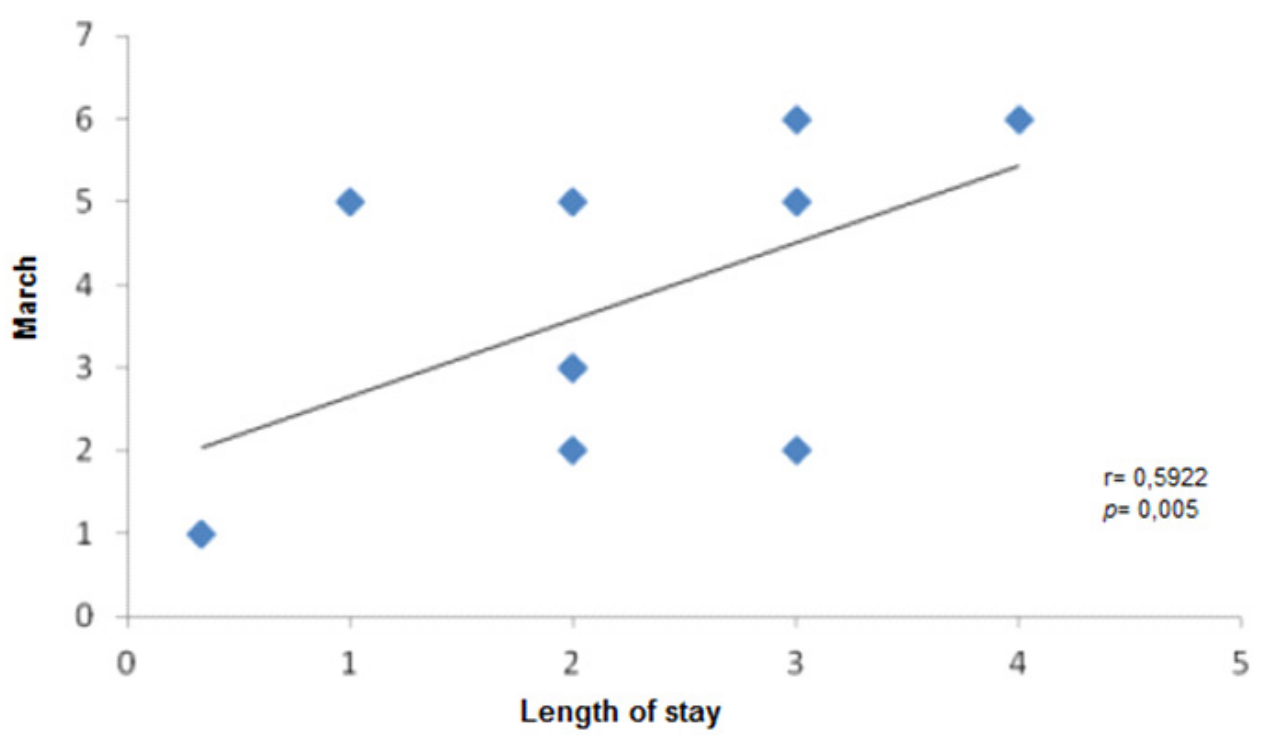

Figure 3: Walker influence of motor development

Independent walking acquisition time with respect to the frequency of child walker use by children in Group A.

For group A could be observed according to Figure 3 time daily use of the device and the time of acquisition of independent walking and statistical significance $(p=0.005)$ between the period of time that the child used the walker daily and the time it took to acquire the ability to move around to the environment without a device support or help of an adult.

\section{DISCUSSION}

The results of this study did not corroborate the evidenced by published research, which to interview parents or caregivers of 291 children aged between 12 and 24 months, found that there was a high number of parents $(68 \%)$ who opted for the use of baby walker because they believe that it contributed to the acquisition of walking and gave autonomy ${ }^{10}$.

Emphasizes that the baby walker has been used by a number greater than shown in the study, despite the contrary recommendations of health professionals, it is estimated that $60-90 \%$ of children aged between six and fifteen months to make its use ${ }^{11}$.

The infant motor development should be considered as a process whose changes follow different phases of instability and stability, influenced by the motor and sensory experiences and increased neural complexity and biomechanical point the child to adapt to different tasks, a process in which discover solutions and adaptations of their movements to meet certain environmental restrictions, with that in the first quarters of life is accelerated plasticity, where large numbers changes happen in a short period of time, and then reach a period of adjustment and improvement of motor skills ${ }^{12}$.

According Darrah et al. AIMS scores lower emphasize the possibility of the acquisition periods of stability and not be characterized as a motor delay ${ }^{13}$, since there is some difficulty in the hierarchy of items, allowing to differentiate children with larger capacities at different positions ${ }^{14}$.

Remember also that each child follows a sequence of landmarks stationary motors, but their rate of motor development is inherent in the environment you live in the tasks performed and their genetics. Thus it takes into account the factor autonomy and environmental stimulation, implementing a development system fixed at various points, which go from this that there is a space for getting the objects that enable and guide this by stimulating this the start/improvement of march, and the free operation of the means for the child ${ }^{15}$.

In a study published comparing the use of baby walker with the start of the march researchers point out that there is a probability on average twice as likely to be a delay in the development milestone in children using the baby walker ${ }^{8}$, however in another observational study of 12 children was observed that they used the baby walker just developing the march than the 
previously used, however, matched against, showed changes in the initial and final leg support contact and tilt the trunk ${ }^{16}$, not finding the body stability in a period considered many instabilities, since the child experiences in his first year of rapid and constant life changes, ranging from locomotor skills to more complex manipulative, characterizing this period as an important period motor development is completed in about two years ${ }^{17}$.

In the study by Angulo-Barroso, Wu and Ulrich ${ }^{18}$ there was a delay in the acquisition of crawling and walking, which may have been influenced by the extremely early use of child walker, between 4 and 6 months, where children do not have specific motor skills to keep the bipedal posture and are too tiny for the walker, preventing your foot is in full contact with the ground, thereby using only his fingertips to get around, creating motor compensation. In this study we did not find about the fact that there is a delay in the acquisition of the march, although children using walker have been exposed to your contact early, at an average of 6.77 months $\pm 1,56$ months.

In an Irish study, it was observed that every 24 hours that remained in use of child baby walker, the child would take about 3.3 days longer to develop the march against departure of those who did not use the equipment ${ }^{18}$, but another study notes that while the independent gait development is closely connected to the motor development, how the family group culture deals with the improvement of the

\section{REFERENCES}

1. Saccani R, Valentine N. Análise do desenvolvimento motor de crianças de zero a 18 meses de idade: representatividade dos ítens da Alberta Infant Motor Scale por faixa etária e postura. Journal of Human Growth and Development. 2010; 20(3): 711-722.

2. Campos D. Desenvolvimento motor axial de lactentes. Saúde Rev. 2004; 6(14): 77-78.

3. Lima CB, Secco CR, Gobbi LTB, Miyasike VS. Equilíbrio dinâmico: influência das restrições ambientais. Rev Bras Cineantropometr Desempenho Hum. 2001; 3(1): 83-94.

4. Chagas PSC. Efeitos do uso do andador infantil na aquisição da marcha independente em lactentes com desenvolvimento normal. Tese (Doutorado) - Universidade Federal de Minas Gerais. Minas Gerais: 2010; p.113-132.

5. Clark JE, Phillips SJ. A longitudinal study of intralimb coordination in the first year of independent walking: a dynamical systems analysis. Child Dev. 1993; 64(4):1143-57. DOI: http://dx.doi.org/10.2307/1131331

6. Sociedade de Pediatria de São Paulo. O mito dos andadores. [cited 2015 Jun 17] Available from: <http://www.spsp.org.br/site/ASP/ materias.asp?id_pagina $=18 \& S u b \_S e c a o=121>$.

7. Rehmani R. Baby walkers-friend or foe. J Pak Med Assoc. 2010; 60(11): 891-892. independence of the child strongly influence early onset or late gait ${ }^{15}$.

The results of the study in the Uruguaiana support expressed by Garrett M. ${ }^{18}$, since the baby walker turns out to limit the transportation of children in the middle, so that it does not enjoy the environmental findings as would happen with children who did not use the baby walker and learned through exploration to know their bodies and limits and discover solutions and adaptations to your movements, this form improving their performance and progressing in their sequential motor development.

\section{CONCLUSION}

The age at which the child acquires independent gait eventually becomes an indicator of autonomy, which may vary according to the socio-economic organization and family culture and environmental stimuli that this child will receive the environment in which it is included, during the development and improvement of motor phase. It was felt that the study results show that the frequency of the baby walker use was similar between the groups and the acquisition of baby walking between the groups showed a significant difference. It is believed that the latter was not affected by the simple approach of using child walker but by the time the child remained in it daily.

8. Vieira M, Ribeiro F, Formiga C. Principais instrumentos de avaliação do desenvolvimento da criança de zero a dois anos de idade. Rev Movimenta. 2009; 2(1): 23-31.

9. Herrero D, Gonçalves H, Siqueira AAF, Abreu LC. Escalas de desenvolvimento motor em lactentes: Test of Infant Motor Performance e a Alberta Infant Motor Scale. Rev Bras Crescimento Desenvolvimento Hum. 2011; 21(1): 122-132.

10. Aburdene RA, Kukoc MC. Relaciones con el inicio de la marcha, gateo, uso de andadores y accidentes. Rev Soc Bol Ped. 2005;44(1): 11-14. 2005.

11. Sociedade Brasileira de Pediatria. Andador: perigoso e desnecessário. [cited 2015 Jun 17] Available from: www.sbp.com.br/show item2.cfm?id_categoria=21\&id_detalhe =2908\&tipo_detalhe $=\mathrm{s}$

12. Toledo AM, Hernandes TS, Rocha NACF, Tudella E. Evidência da transição de fases no desenvolvimento do controle cervical na postura prona. Temas Desenv. 2005; 13(78): 19-21.

13. Darrah J, Hodge M, Magill-Evans J, Kembhavi G. Stability of serial assessments of motor and communication abilities in typically developing infants-implications for screening. Early Hum Dev. 2003; 72(2): 97-110. DOI: http://dx.doi.org/10.1016/S0378-3782(03) 00027-6 
14. Liao PJ, Campbell SK. Examination of the item structure of the Alberta infant motor scale. Pediatr Phys Ther. 2004;16(1):31-8. DOI: http://dx.doi.org/10.1097/01.PEP.000011 4843.92102.98

15. Rabinovich EP, Carvalho AMA. Modo de vida e relação mãe criança: um estudo do andar. Rev Bras Crescimento Des Hum. 2001; 11(1): 11-23.

16. Mascarelo LO, Silva J, Silveira TM. Análise da fase de apoio da marcha em crianças que utilizaram andador. [cited 2012 Jan 15] Available from: http://www2.rc.unesp.br/ eventos/educacao_fisica/biomecanica2007/ upload/

\section{Resumo}

Introdução: A aquisição do desenvolvimento normal infantil está relacionada com as experiências sensóriomotoras vivenciadas em seu primeiro ano de vida. Como recurso de estimular a marcha, os pais acreditam que o andador infantil possa facilitar esta prática. Objetivo: Verificar a frequência da utilização do andador infantil por crianças de até 18 meses em duas escolas de educação infantil do município de Uruguaiana-RS. Método: Partiu-se de uma pesquisa de campo, quantitativa com abordagem exploratória, onde os pais responderam um questionário quanto à utilização ou não do andador. Resultados: O tempo de uso diário influenciado no tempo de aquisição pé ( $p=0,005)$; e não houve associação entre os grupos que usaram ou não usar o andador em comparação com o seu desenvolvimento motor de corrente avaliada por Alberta Infant Motor Scale $(p=0,566)$. Conclusão: Concluímos que o período de aquisição da marcha está no uso diário do andador, que é um fator importante para essa aquisição.

Palavras-chave: crianças, desenvolvimento infantil, andador. 